\title{
Digital Sclerosis? Wind of Change for Government and the Employees
}

\author{
KIM NORMANN ANDERSEN, Copenhagen Business School \\ JUNGWOO LEE, Yonsei University \\ HELLE ZINNER HENRIKSEN, Copenhagen Business School
}

\begin{abstract}
Contrasting the political ambitions on the next generation of government, the uptake of technology can lead to digital sclerosis characterized by stiffening of the governmental processes, failure to respond to changes in demand, and lowering innovation feedback from workers. In this conceptual article, we outline three early warnings of digital sclerosis: decreased bargaining and discretion power of governmental workers, enhanced agility and ability at shifting and extended proximities, and panopticonization. To respond proactively and take preventive care initiatives, policy makers and systems developers need to be sensitized about the digital sclerosis, prepare the technology, and design intelligent augmentations in a flexible and agile approach.
\end{abstract}

CCS Concepts: • Social and professional topics $\rightarrow$ Employment issues; Automation; Socio-technical systems; Privacy policies; Governmental surveillance; Governmental regulations;

Additional Key Words and Phrases: e-Government, public sector, digitalization, digital sclerosis, workplace, work, future work, changing nature of work

ACM Reference format:

Kim Normann Andersen, Jungwoo Lee, and Helle Zinner Henriksen. 2020. Digital Sclerosis? Wind of Change for Government and the Employees. Digit. Gov.: Res. Pract. 1, 1, Article 9 (January 2020), 14 pages.

https://doi.org/10.1145/3360000

\section{INTRODUCTION}

"The future is in the air

I can feel it everywhere Blowing with the wind of change"

(Scorpions, 1990)

Klaus Meines and the Scorpions' world-hit "Wind of Change" from 1990 were singing out loud that "the wind of change blows straight into the face of time" [1]. The tunes illustrate well the eagerness government sensed responding to the .com and digital development that had spiraled in the private sector. Despite, or perhaps due

Author's addresses: K. N. Andersen, Department of Digitalization, Copenhagen Business School, 60 Howitzvej, DK - 2000 Frederiksberg, Denmark; email: andersen@cbs.dk; J. Lee, Graduate School of Information, Yonsei University, Seoul, Korea; email: jlee@yonsei.ac.kr; H. Z. Henriksen, Department of Digitalization, Copenhagen Business School, 60 Howitzvej, DK - 2000 Frederiksberg, Denmark; email: hzh.digi@cbs.dk.

Permission to make digital or hard copies of all or part of this work for personal or classroom use is granted without fee provided that copies are not made or distributed for profit or commercial advantage and that copies bear this notice and the full citation on the first page. Copyrights for components of this work owned by others than the author(s) must be honored. Abstracting with credit is permitted. To copy otherwise, or republish, to post on servers or to redistribute to lists, requires prior specific permission and/or a fee. Request permissions from permissions@acm.org.

(C) 2020 Copyright held by the owner/author(s). Publication rights licensed to ACM.

2639-0175/2020/01-ART9 \$15.00

https://doi.org/10.1145/3360000

Digital Government: Research and Practice, Vol. 1, No. 1, Article 9. Publication date: January 2020. 
to, the crash of the .com hype, digital enthusiasm of pushing technology to the servers of government were in full bloom. At the turn of the 21st century, government at local, regional, and national levels were seeking guidance on how to get inspiration from other governments and input to how government could adopt online services to become more accessible, accountable, and transparent. Consequently, a number of maturity models emerged, and the author team of this article were among those academics bringing some of the most quoted maturity models to the table offering an approach to move forward with digitalization $[2,3]$.

On the brink of the 2020s, there are many similarities with the turn of the century. First, there are numerous digital legacy systems. An installed base of technologies needs to run continuously and be maintained, along with adoption of breakthrough emerging technologies. Thus, whereas there are expectations that block chain, cloud, artificial intelligence (AI), and robots will do good for government in the 2020s what the Internet did to government in the 1990s, we need to pay attention to the fact that adoption of the Internet was not a straightforward process due to the need of continuity and interfacing with the legacy systems in proprietary format and ownership of code and data. Second, government is facing a development in the private sector with cognitive technologies and second machine age technologies [4-7]. Many of the technologies are part of inflated expectations at the Gartner hype curve, quite similar to how Internet technologies were at the end at the 1990s. In our view, there will be a coming phase of disillusionment of the second machine age technologies in the private sector that will create strong push from suppliers and consultants on the public sector to adopt the technologies. Third, there is strong similar faith in the power of strategy and formal decision on the uptake of technology. Although research has shown that it is a misconception that eagerness and e-government progressiveness will lead to the uptake of future technologies [8], on the brink of the 2020s government is launching strategies and actions plans with high ambitions similar to those in the wave of strategies pushed by, for example, the Al Gore administration's 1997 Access America strategy and Tony Blair's e-government cabinet replacement of the e-envoy in $2004[9,10]$.

This conceptual article stands on the shoulders of decades of research that has failed to demonstrate empirical verification of technology-driven radical administrative transformation. Contrasting political ambitions of digital government transformation, our key proposition is that uptake of technology can lead to "digital sclerosis" characterized by stiffening of the governmental processes, failure to respond to changes in demand, and lowering innovation feedback from workers. Decreased bargaining and discretion power of governmental workers, enhanced agility and ability at shifting and extended proximities, and panopticonization are observable symptoms of digital sclerosis. To respond proactively and take preventive care initiatives, both policy makers and systems developers need to be sensitized about digital sclerosis, prepare their organizations for bundles of technology instead of each technology separately, and use more agile approaches with built-in flexibilities in designing intelligent augmentations instead of complete digital automations.

We begin the article by outlining the winds of technology changes and how maturity models have been able to capture these changes, only up to certain points. We then proceed to outline the causes and symptoms of possible digital sclerosis. In the closing sections, discussions are made concerning how the future research agenda on e-government might incorporate this idea of digital sclerosis and engage with operational practices and citizens in responding to these challenges.

\section{WIND OF CHANGE: COMING PARADIGM OF NEW TECHNOLOGIES}

Most e-government maturity models developed around the beginning of this century were focused on data and system integration as key objectives to reach. Potent arguments for the integration efforts include e-services that can share data, minimizing data redundancy, improving data quality, and detection of fraud and abuse. Our proposition is that technological integration of system and data is vital to keep in focus. Government as a platform is offering new approahces to mapping data infrastructures. In addition, the exclusive focus on in-house and governmental system data integration can be counterproductive to objectives of being innovative and responsive

Digital Government: Research and Practice, Vol. 1, No. 1, Article 9. Publication date: January 2020. 
to new demands from society developing alternative business models for how and where governmental services are operating, because the public-private distinction can be leveled out by technological solutions. Although not complete, the integration and/or connection across different platforms are now feasible when necessary, and government digitalization is now entering a new era of disruptive innovation in which values are playing important roles in directing operation and service transformation beyond integration of technical infrastructure.

New technologies come under many hats: smart manufacturing, the fourth Industrial Revolution, the second machine age [11], the platform economy [12], and the sharing economy [13], among others. For more than half a century, automation and technology have been heralded and heavily discussed whether and how the technologies are bringing about fundamental changes to the economy [14], industrial work environment [1519], and management [20].

Although the dynamics of computing can be more vibrant, visible, glamorous, and more leaping forward in the private sector, the government scene of information technology (IT) use has been shifting as well, and theory and practice are short of knowledge as to whether there is a possible unified pattern of changes and what the impacts are on nature of work and the role of workers and their managers in government in the same way as in the private sector. Managers in government in the 1970s were equally uncertain about the nature of changes and how to respond to use of "office" technologies [21]; however, the uncertainty of technologies 50 years later encompasses a plethora of technologies with citizens, companies, and politicians using what used to be technologies for experts and specialists. Although there is diffusion of technology to a broader group of users and possible empowerment of citizens and government workers, institutional interests appear to have the upper hand in the utilization of social media, AI, robotics, sensors, and data analytics.

Contrary to policy statements and framing in the media, empirical evidence on digitalization and job loss is multifaceted and inconclusive. Herbert Simon noted in the 1960s that the inflated expectations of the transformative power of automation was unjustified. Simon argued that, by most accounts, there was nothing new under the sun compared to the mechanization of industries that took place about 30 years earlier. Yet, he did acknowledge that the spread of new technologies to offices and beyond would challenge workers and managers [20]. In our view, there is good reason to recall Simon's analysis in discussions around the potentially radical and disruptive effects of digitalization. Thus, it is questionable whether there is any evidence for e-government being a driver for administrative reforms and changes [22,23]. Based on a comprehensive literature review, two of the nestors of e-government research (John King and Kenneth Kraemer) concluded that "information technology has never been an instrument of administrative reform; rather, it has been used to reinforce existing administrative and political arrangements" [23]. Yet, there are indicators that the nature of government and the job functions employees are performing are changing.

In managing government organizations, there has been a push for being innovative and simultaneously delivering efficiency and demonstrating effectiveness in terms of providing services to citizens, as well as optimizing administrative operations. In this regard, since the advent of computing technology, governments have been making efforts to computerize their operations and citizen services. Information and communication technology (ICT) in government has been part of these efforts in lowering administrative burdens and bettering citizen services [24], as well as making government more transparent, accessible, accountable, open, and inclusive, and preventing corruption [25].

In public administration, improving efficiency and effectiveness of operations and services has been the focal point of practice. ICTs have been considered important in achieving these goals. In this regard, governments worldwide have been making efforts to develop and implement e-governments since the advent of computing technology. As for guiding the e-government development, a variety of maturity models were developed and used since 2000. Most of these models include integration as the final stage. Interestingly, it seems that technologies have become more and more integrative, as can be seen in the characteristics of recent technologies, such as cloud computing, Internet of Things (IoT), big data, social media, and AI. 
The new technologies are based on "integrated" platform-based operations accessing data and other resources from other systems in real time. Thus, the characteristics of these new technologies are different from those we had before. Systems and technologies have become truly ubiquitous, and even intelligence is expected to be built into the systems and networks. AI is predicted to replace humans even in highly cognitive jobs. Now, systems are implemented and connected to each other on a scale that has never been imagined. At the same time, the negative side of these integrative technologies is also becoming more and more eminent. In some cases, people are losing discretions and power once systems are in place. It has happened in rare occasions in the old paradigm, but in this new paradigm of abundant technologies with intelligence, services and operations might be stiffened, especially from workers' viewpoints. Paradoxically, this might be caused by those integrative technologies that supposedly are freeing humans from tedious tasks.

Systems development for government operations and services is generally larger in scale and scope. Governmental operations and services are more expansive and inclusive of different aspects of life compared to business operations that usually are focused on specific sets of products and services [36]. In addition, as most governments consist of different levels, such as local and central, a high degree of complexity is involved in implementing systems across different levels and functions.

In this regard, e-government research has developed a variety of highly cited maturity models throughout the history of government digitalization. Whereas the Layne and Lee [2] model maps the degree of integration and the organizational complexity, the Andersen and Henriksen [3] model outlines the degree to which the digital services are focused on bringing benefits to the citizens and their relation to the core activities of government. Layne and Lee [2] provide an internal view of maturity, whereas Andersen and Henriksen [3] focus on an external and outside-in approach to maturity.

Since the publication of Layne and Lee [2] and Andersen and Henriksen [3] models, which, combined together, have been quoted about 4,000 times, there has been a methodological stream of research that focuses on a more rigorous data analysis and the ability to account for multiple paths to maturity [26]. Yet, the methodological stream is still dominated by top-down approaches, with few attempts to develop bottom-up approaches [27]. In addition, a range of scholars have populated and refined the stages of the maturity models, outlining the path of entity toward maturation, including defining the stages and the relationship between each of the stages [28, 29].

In most e-government maturity models, integration is positioned as a key foundation stage of technological systems development. Out of 12 maturity models reviewed, 7 models place integration as the last stage [30]. Electronic governance has been conceptualized as a system that changes and evolves, and e-government is proposed as a maturity model generally defined in a few stages, and in general the last stage is technological integration. In this regard, e-government seems to be conceptualized as initially aiming at integration and linkage by classifying the development of a technical system. Furthermore, there have been formulated radical propositions of a government have been formulated as a platform (UK Government Digital Service and Code for America) and digital era governance replacing new public management governance [31].

Based largely on this notion of integration as the targeting stage of e-government development, the United Nations (UN) developed an electronic government survey in 2001 and started benchmarking governments worldwide [32]. The initial survey in 2001 began with an underlying model consisting of four stages, including "transaction" as the last stage, but later added networked presence after transaction [33], and changed networked presence to connected governance [34]. In addition, a separate e-participation index was developed and measured, indicating different dimensions of this behavioral matter of citizen participation.

Digital transformation of government using digital technologies started decades ago. In Korea, the 50th anniversary of computing in government was celebrated in 2017 [35]; in Denmark, the first computer for government came in 1948 with Marshall Aid in the postwar period [36]. Government digitalization coincides with technological development of ICT and also transformations in the private sector. In the early stages of IT adoption in e-government, the computerization of mundane tasks was the target. This initial conceptualization of automation of routines has given way to informatization and transformation in the later stage as more elevated goals of

Digital Government: Research and Practice, Vol. 1, No. 1, Article 9. Publication date: January 2020. 


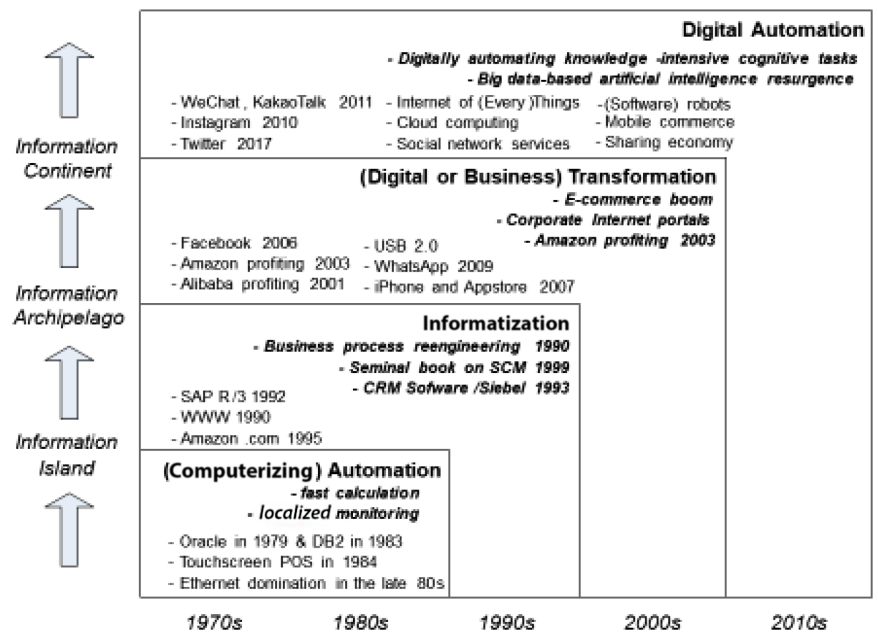

Fig. 1. Winds of Digitalization, 1970s-2010s. (Modified from Lee and Moon [41].)

IT utilization [37] with further technical developments. It seems that technologies have finally become maturely integrative enough beyond simple transformation, as can be seen in the characteristics of recent technologies, such as cloud computing, IoT, big data, social media, and AI. Even the UN e-government index abandoned the maturity model in 2014, indicating the new paradigm. These technologies presuppose platform-based operations. Indicative of this development, the maturity aspects of the UN e-government survey have been cast off, and the title was changed to E-Government Development Index (EGDI). EDGI was announced as an independent but interrelated three sets of indices-online service index, telecommunication infrastructure index, and human capital index-although the e-participation index was kept as a separate measure.

"The 2004 and 2005 editions of the Survey captured the state of a country's readiness for e-government. However, in $2008, \ldots$ as 'readiness' was not deemed to adequately reflect the need for concrete implementation on the ground, the publication changed its focus from assessing readiness to assessing actual development. In 2014, 'e-government maturity' was viewed as obsolete since e-government goals and targets are constantly evolving to deliver and surpass what the public expects" [38, p. 11].

All of the hassles that each system should have been enduring with the proprietary format of data and applications were eliminated, as most systems started to communicate via the Internet. "Porting" between systems became nonproprietary [39]. Information continents are being introduced as the basis for new ideas for operations and services, leading to new business models [40]. Now, our online world is being operated on these continental platforms, composed of module-based APIs with standardized databases. Digital technologies have significantly evolved from stand-alone number crunchers into interconnected intelligence. As the development continues, technologies are supporting, supplementing, and beginning to replace human tasks and capacities with big data analytics capability and IoT sensing data collection capability, entering a new world of "digital automation" (Figure 1).

"These technological developments are metaphorically described as the formation of information continents: from information islands via information archipelagos to information continents. This metaphor weaves the historical development of digital technologies: transitioning from building functional information systems (islands) to connecting these functional systems via network connections for information integration across different functions and organisations (archipelagos) and then forming base platforms of operations (continents) on which new and innovative services are developed. This progression takes advantage of the nature of information synthesis, as information becomes more meaningful and useful when connected with other information" [41, p. 22]. 
Table 1. Winds of Technological Change in Government

\begin{tabular}{ll}
\hline Conventional Approach & \multicolumn{1}{c}{ Winds of Change } \\
\hline Routine & Intelligent \\
Stand-alone & Interconnected \\
Single context & Infused through all contexts \\
Fragmented & Integrative \\
Detached & Immersive \\
Single purpose & Multipurpose \\
\hline
\end{tabular}

Digital automation in this regard presupposes the existence of information continents from which data, applications, and other resources are readily available. As the metaphor suggests, technological characteristics of information continents are different from those of information island. In Table 1 we have summarized the key differences between the conventional approach (information islands) and the winds of changes. The most critical difference in terms of characteristics is the integration of data that can easily be accessed and utilized by anyone with authority. In addition, the other side of this integrative trait of information continents is the strong emphasis on services. As the demand for information increases, each information continent will be working on increasing the service capabilities related to its data and applications. Some proprietary information with privacy requirements might be hidden from the outside, but these continents will be working with open data orientations as new business opportunities exist. The synergy created by combining information from different sources is so strong that it is not easy to dismiss this synergy and keep information private. The pressure will become higher as digital automation progresses.

Thus, this continentalization of information is enabling the new wave of automation: digital automation that includes a higher level of intelligence. Different from automation that we have experienced in mechanical automation, digital automation includes intelligent functionalities that were once thought could only be done by humans. With big data available on these continentalized platforms that have been accumulated by way of IoT, social media, and mobile computing, the intelligence capability of machines can be improved up to the level of actual execution of procedures without taking high levels of risk. Thus, the information continents are the foundation of digital automation.

Digital automation is expected to transform the public sector at least as much as the private sector, as it can easily be applied to the decision-making processes and delivery of public services [42, 43]. Governments are seeking alternative approaches to more efficient and effective public service innovation by catching up with the latest trends. For example, governments are contemplating how to utilize big data and machine learning technology for better decision making and policy implementation, as well as stimulate digital automation to incite innovation.

Whereas studies on the uptake on machine learning, AI, robots, and robotic automation processes (RPAs) in local government are still relatively few [44], technologists and economists agree that AI technologies will have a profound effect on the nature of work and the availability of employment opportunities in the coming decades $[45,46]$. Although these technologies are still under fast-paced development, they portend radical changes. Corporate investment in $\mathrm{AI}$ is growing fast; it is estimated that technology companies spent between $\$ 20$ billion and $\$ 30$ billion in 2016, with more than 90\% of these investments still at the R\&D stage [47]. Outside of the technology sector, early-stage experimentation in a variety of industries, from manufacturing to services, is revealing the potential for AI to transform jobs and skills. Some jobs are disappearing, whereas new ones are emerging [48].

Although these technologies promise benefits to the economy in the form of improved productivity and growth and the enactment of distributed coordination [49], they also bring with them several challenges to business and society. Business processes are increasingly conducted as a virtual-physical mix, leading to a complex division of labor among machines and humans. This division of labor may require rethinking of the basic

Digital Government: Research and Practice, Vol. 1, No. 1, Article 9. Publication date: January 2020. 
assumptions of work. It is unclear as to how these changes will play out and how the workforce of tomorrow would need to be reskilled to exploit AI rather than be replaced by it.

The technological breakthroughs also raise a number of concerns about their possible negative impacts on society. As shown in the Luddite movement after the Industrial Revolution and the Blue-Ribbon National Commission on Technology, Automation, and Economic Progress launched by President Johnson in 1964, anxiety over the replacement of human jobs by machines remains an important agenda in society [50]. Whether the positive social impacts of new technologies outweigh their negative counterparts by enhancing overall productivity and creating new businesses, new jobs, and new opportunities has been long debated [50].

The second machine age technologies [11] may surpass those of the previous wave of mechanization, routinization, (analogue) automation, informatization, and (digital) transformation. Digital automation includes examples such as the New York Times experimental AI project, known as Editor. By searching through data in real time and extracting information based on requested categories, such as events, people, locations, and dates, Editor can make information more accessible by simplifying the research process and providing fast and accurate fact checking, and the Washington Post experimented with Heliograf during the Rio Olympic Games in 2016, which generated news stories by analyzing data about the games as they emerged.

The potential impact of AI and software robots could irreversibly transform the nature of daily work for both blue- and white-collar workers [6], altering skilling/deskilling processes and eventually career paths [45, 51]. According to a McKinsey Global report [47], AI-powered technology has already outperformed humans in certain business processes (i.e., forecasting, automated operations). Approximately $60 \%$ of occupations are expected to have at least a $30 \%$ proportion of business processes that could be augmented or replaced by AI technologies. This is also forecast to occur in a governmental setting and the (expert) professions employed thereof [6]. It is against this backdrop that we discuss the three powerful forces of digitalization: radical shifts in job contracts and the bargaining power of workers, connectivity of the extended workplace, and monitoring of work.

\section{CAUSES AND SYMPTOMS OF DIGITAL SCLEROSIS}

\subsection{Causes of Digital Sclerosis}

Capital-intensive work practice in the public sector office environment is providing a market for the software and hardware industry. For example, in Korea, this is very visible with a world-class technology sector that uses the Korean e-government portfolio as a showcase and display window. In addition, Korea's story is really about the government's decision to buy advanced technologies from Korean companies, even though they did not yet have them to sell. This meant a massive public investment in R\&D to create a capacity for Korean companies to supply the government's needs [52,53].

Although the term digitalization dates back to the early 1970s [54], the widespread use of the term and the associated government strategies, budget allocations, and implementations have escalated in the post-IT hype era. Here we argue that digitalization is moving ahead with a speed and a self-sustained hyper-cyclonic spiral that may lead to digital sclerosis, requiring urgent policy responses. Although a free market and the principle of the invisible hand, with regard to the advance of digitalization, had major strengths and helped digital economies move forward, there seem to emerge capital-intensive work practices oppressing workers and labor in a way that we did not anticipate in developing technologies. This calls for immediate and critical policy responses to compensate for the side effects that we may have not anticipated and prepared for. At this stage, we stand at the sideline and observe the emerging consequences of the invisible digital hand and do not yet have the capacity to identify nor enforce the policy responses or mechanisms compensating for the side effects of emergent capitalintensive work practices.

In medicine, sclerosis occurs because of poor blood flow, possibly caused by diabetes. The finger joints become stiff, and the skin on hands and fingers becomes thick and tight. We propose that digitalization can lead to similar 


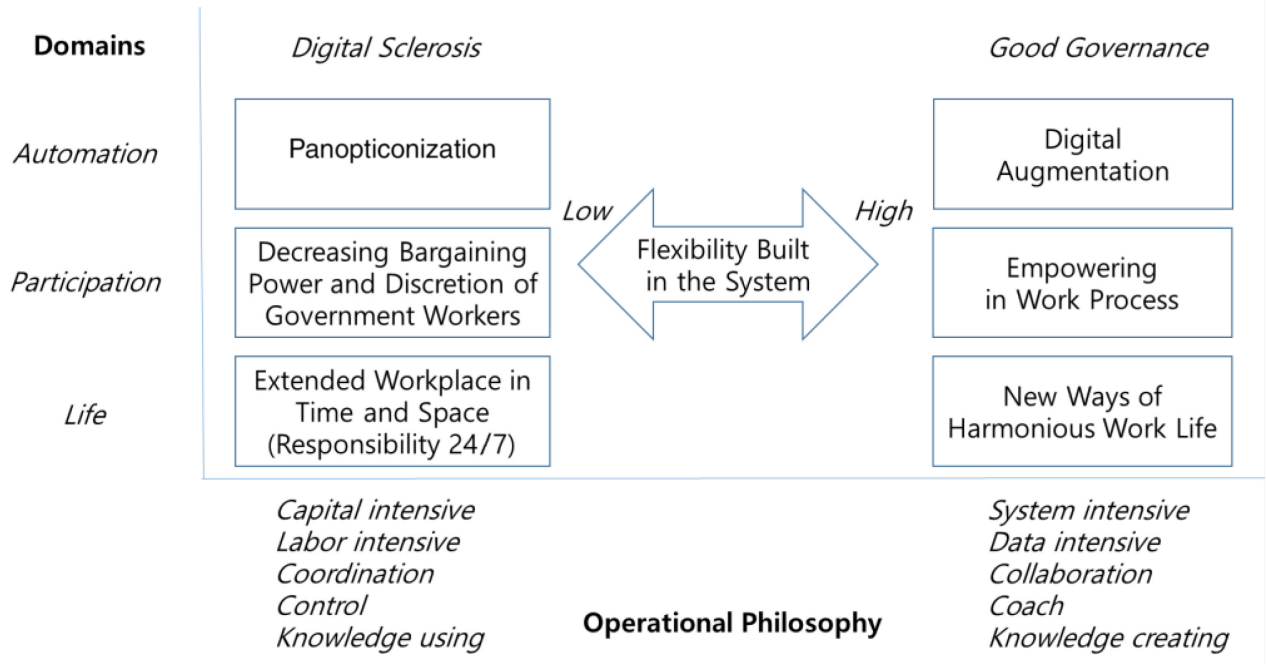

Fig. 2. Digital sclerosis versus good governance.

effects on humans in the workplace. Workers can be empowered and become much more productive with the help of new technologies, products can be improved, and innovation can take entirely new roads. Yet, it is also a risk that the emergence of powerful technologies such as big data analytics, AI, and machine learning, along with robotics, RPAs, IoT, and combinations of those technologies not seen yet in the market, can lead to an irreversible situation where machines win the race and humans lose control, leading its way into a variety of unanticipated consequences. For the purpose of our argument in this article, we define digital sclerosis as "the stiffening of work, usually caused by a replacement of the normal human work with digital work."

\subsection{Symptoms of Digital Sclerosis in Government}

Digital sclerosis does not occur out of the blue or by some magic power. Our proposition is that there are three distinct and early warnings of digital sclerosis: decreasing bargaining and discretion of governmental workers, extended workplace in time and space, and panopticonization. In the following sections, we will detail each of the symptoms. Also, the symptoms of digital sclerosis and possible response (good governance) are summarized in Figure 2.

3.2.1 Decreasing Bargaining and Discretion of Workers. With the advance of IT, tasks that used to be meaningful work assignments are becoming obsolete, excluding a growing number of people from the labor market. When tasks beyond the capacity of software robots appear, digital platforms with an unlimited workforce are at hand: they create a space for skilled people to offer their services in a market of time-limited assignments, independent of time and space. In the long run, however, it prevents many from getting a strong foothold in the labor market, all in the name of the sharing economy. Apart from unstable income, the precariat potentially have limited access to healthcare benefits, unemployment insurance, and retirement schemes [55].

Some platform evangelists praise the opportunities of the precariat workers as creative and knowledge-based work [12], whereas others paint a gloomier picture [55]. The gloomy side warned about an emerging class of people facing insecurity and that people may be moving in and out of precarious work already. The implications for people are critical and enormous in both economic and social aspects. German workers exposed to robotization at their workplace keep their jobs but lose their bargaining power and have less income growth than other workers [56]. Office workers, healthcare professionals, bankers, and lawyers face that machine learning 
and robotics are entering their offices. Contrary to their human counterparts, they are not hanging out at the cafeteria or coffee machine or taking bathroom breaks.

In addition, many jobs are taken away from humans, and humans are becoming subject to heteromation [14], being alienated from the core values of work. Consumers are orchestrating the development by the marketing and consumption of their own products in digital platforms that are connecting networks of peers who are rating, recommending, and ranking products [12], paying with their own time and effort. There would be not much room for services with face-to-face personal touch. Personal touch might be considered a nuisance.

Customer service is one of the areas in which it is important to empower frontline managers so that they can handle customer complaints promptly with adequate emotional accommodation of perplexed customers. However, in most online customer services, the systems are responding without much flexibility of accommodating customer requests, and/or without the discretion of frontline managers. In contrast to an offline customer service counter in which service representatives can be empathetic about a customer's situation and do something to compensate his or her frustration, online responses generally are more rigid and inflexible. Robotization might have this kind of impact on governmental processes and services.

These can also be found in governmental services. Due to transparencies promised by IT, an officer's discretions are taken away once the systems are installed with simplified rules that can be managed by automated processes [57]. Although the theme of discretion in government original was developed as part of the implementation of decisions [58], e-government literature has emphasized the potential of IT to decrease corruption and accommodate government services rather than policing and regulating types of government [59,60]. Thus, technologies are, supposedly, to increase and enhance the service quality but not decrease. The coldness that citizens have experienced with governmental bureaucracy should not be exacerbated with more technologies.

3.2.2 Extended Workplace in Time and Space (Response-ability for 24/7). The first generation of digital connectivity was labeled outsourcing with its vocabulary of off-shoring, far-shoring, and near-shoring. Connectivity is known to reduce the temporal and spatial distance. The sentiment of that movement is captured in the bestselling book The World Is Flat [61], where distance work becomes part of the corporate vocabulary. Now, we are witnessing a second generation of digital connectivity that expands the work space, with asynchronous and synchronous tools such as Skype and FaceTime. This second-generation connectivity not only reduces the temporal and spatial distance between workers and organizations but also increases the synchronicity of interaction with infiltration of mobile devices and IoT services. Instant messengers are bogging down workers with realtime notice of messages and agitates their work-life balance. This second generation of digital connectivity puts new pressures on the workforce with its blurred division between work and leisure, creating expectation of 24/7 availability instead of 9 to 5 as a weekly working schedule [62].

The extension of the workplace occurs in time and proximity. With regard to time, the expansion via technologies is predominantly deployed with asynchronous purposes. The government employees are present in physical spaces but communicating with the citizens with asynchronous technologies. Thus, technologies are not applied to decrease the difference in time and space but to increase it.

Transparency driven by social media exposing vulnerable flanks of organizations with "shitstorms" and transnational movements, such as the recent \#metoo campaign, are challenging managers' ability to be in control of their company. However, this extension of work hours may also infiltrate the work-life balance. There is a ban on managers' calling and emailing employees beyond working hours. They have noticed the sustaining work stress beyond work hours, and everybody kind of becomes on call 24/7.

3.2.3 Panopticonization. Although cases of panopticonization, in which an employee's privacy or a citizen's privacy sphere is invaded and violated, are not a new trend [63] and have been used in studies on, for example, electronic panopticon in the shape of CCTV [64] or a novel theoretical concept $[37,65,66]$, there is booming of and a great variety of software emerging [67] and spectacular cases such as this example: "the Food and Drug 
Administration started spying on a group of agency scientists, it installed monitoring software on their laptop computers to capture their communications" [68].

Digital behaviors are transferred from the personal space to an organizational context. The tools for connectivity are utilized for daily operations along with other aspects of digitalization. Mechanisms for monitoring work and workers are put in place, for both employees and clients, to optimize and streamline interaction. Software robots are taking over the trivial tasks traditionally undertaken by clerks and, by constantly feeding IT systems, $\mathrm{AI}$ and machine learning are becoming part of the organizational fabric of society [69].

Both governments and private organizations are operating on platforms rather than individual information systems. This continentalization of information [70] only happens with proliferations of the Internet technologies and smart devices being connected to the Internet. Working on information continents demands the changing nature of work-changing the work practices that are developed and employed based on industrial technologies.

Such changes include a new landscape of technologies, involving the use of social media for formal and informal communication in both the citizen-government and government-citizen interaction space, bringing new perspectives to the realm of maturity models in public administration. The increased role of social media in public administration has been addressed in relation to the communication patterns between citizens and the public sector under the label Open Government [71], specifically in relation to involvement and participation, or in the context of crisis situations where a quick response from government is required [72] and where social media input from citizens is ideal. Less attention has been focused on how government workers' and governmental organizations' work practices and communication patterns are transformed and which role social media plays in the transformation of the digital interaction within and beyond the organization.

\section{BUILDING THE RESEARCH AGENDA}

In this article, we have argued that the 2020s will share many similarities with the sequence of events that took place in the late 1990s and first years of the new millennium. It means that there must be good opportunities for researchers to pursue in terms of the changing nature of work with the advance of ICT. We are not sure at this point how much of the nature of work will be changing, but conjectures can be made about future changes based on what is happening now, and we can prepare ourselves in terms of policy readiness.

Formulating a research agenda for the 2020s, however, is also very different from doing so 20 years ago. The research community is much more integrated and diffused in many parts of the research that feeds into the areas of public administration, information systems, sociology, law, and so on. In addition, there are several interdisciplinary journals and special issues of discipline-focused journals that take on board the digitalization of government.

Our call for a revised research agenda includes empirical and theoretical work largely related to the three symptoms of digital sclerosis: decreased bargaining and discretion power of governmental workers, enhanced agility and ability at shifting and extended proximities, and panopticonization. In this regard, our propositions for research are related to the possibility that digital sclerosis might be occurring throughout the intensive digital transformation that is expected to be happening from this point of human history, using advance intelligence technologies. We are suggesting that three symptoms are somehow showing up as antitheses against what the new management theories are currently proposing in the future. Here, therefore, we are comparing and contrasting possible digital sclerosis with expected good digital governance.

First of all, one of the symptoms of digital sclerosis is cited here as panopticonization. With increased monitoring capability provided by IoT sensors and connected devices worldwide, now there are strong possibilities that human behaviours can be monitored in a more precise manner. Panopticonization emphasizes the negative side of this technological capability. This may bring forth the idea of government authorities invigilating citizens or a company monitoring employees. However, considering that monitoring is not a good way to enhance

Digital Government: Research and Practice, Vol. 1, No. 1, Article 9. Publication date: January 2020. 
productivity, monitoring capabilities can be put into good use in terms of augmenting what humans are missing at work. Monitoring is the first step of digital augmentation. Paradoxically, contrary to common concern about the situation presented in Orwell's 1984, the augmentation of human capability with a numerically controlled intelligence machine would not be feasible without some kind of monitoring capability. Systems need to be built, whether ICT based or in physical reality, with a bit of flexibility in which our values can be reflected. The systems we are building from this point have to have flexibility of being easily reconfigurable and be modular in the sense that we can easily modify routines depending on the context and changes in the context.

Second, if the system works toward decreasing the bargaining power of an employee, we would not be able to see employee empowerment that is expected to be the basic principle in managing the knowledge workers of the future. With advanced ICT, even mundane jobs are becoming knowledge laden and knowledge creating. The knowledge we are talking about here is not heavyweight knowledge that goes into an encyclopedia but is very lightweight knowledge such as a comparative insurance premium contextualized for individual situations or insights on improvements in service operations. Even most service frontline workers are conducting knowledge-based tasks. Knowledge workers' knowledge would be activated better when they feel motivated but not when they feel forced into the situation. Thus, the systems that we are building from now on for these knowledge workers need to reflect these empowerment principles rather than controlling the employees' bargaining power.

Third, workers in government connect to work via ubiquitous mobile devices on the Internet. They are exchanging emails and messages via instant messengers and posting on various types of social network services: Facebook, Instagram, and even company-provided internal social network sites. They are getting directions, instructions, answers, and questions even in the middle of the night. In online communications, some channels are designed to be asynchronous, meaning that the message does not have to be delivered and read in real time. For example, most email servers do not poke and alert users when new mail comes in, or at least users can disable these kinds of alerting features, but most people, intoxicated by online spontaneity, leave these features on and use email as instant messengers. In some sense, workers are on call 24/7. Some companies are implementing policies banning messages after regular work hours, but this does not work in most cases. With knowledge work in which physical boundaries do not matter much, your collaborator might be residing on the other side of globe. In the old days, you reserve time slots for calls with people in other time zones, but in this world of constant connection with a variety of channels with different characteristics, you are sending messages instantly, by definition, when thoughts come to your mind. You would not be able to blame senders for sending messages at odd times, because if senders wanted to be considerate of recipients, they would need to send the messages in their own time zone. Thus, the work-life balance in terms of segregating working hours from one's personal life does not work as we have conceived. Now, the management and workers need to figure out how to harmonize their work life and personal life. Receiving messages and responding instantly or needing to work on it when it requires time to think and process creates knowledge. Employees need to be able to figure out how to deal with their personal life being mixed with their professional life. In addition, the systems need to have these harmonization features built in.

\section{CONCLUSION AND IMPLICATIONS FOR RESEARCH AND PRACTICE}

This article offers contributions to theory and practice. At the theoretical dimension, our work contributes to the conceptual grounding of directions of uptake of IT in government. Although maturity models were potent in delivering input to practice, theoretical and empirical soundness were questioned in the academic literature. This work is an attempt to stimulate academic grounding at the early stages of the wind of technological change in government. We propose that the research community focuses attention on the three key components of the digital sclerosis triangle model: bargaining and discretion mechanism and power of the workers, shifting and multiple proximities of services, and panopticonization through uptake of cognitive technologies.

Digital Government: Research and Practice, Vol. 1, No. 1, Article 9. Publication date: January 2020. 
The early warning signals of digital sclerosis will spell out differently in government. Whereas the policy ambition of digitalization of government might more be driven by ambitions to foster innovations that can generate jobs in the export industry and improve security, other governments with the ambition to radically transform the administration might be more prone to symptoms of digital sclerosis outlined in this article.

The three forces of digital sclerosis call for policy action. Our proposal is to first acknowledge that radical shifts in job contracts and the bargaining power of workers have already occurred, as well as ensure that policies are formulated that positively change this development.

Second, the extreme connectivity of the extended workplace creates unique possibilities to empower citizens and workers; this needs to be promoted to replace the exploitative path that digital sclerosis has taken thus far.

Finally, managers and policy makers are to formulate responses on the monitoring of service and work. Not only should this be done in the interest of the workers, but it also should be a road map for how managers can refine their role and functions in the digital age. By many accounts, operational management functions such as delegation of work and output control are being taken over by machines, leaving management short of control.

\section{ACKNOWLEDGMENTS}

We are grateful for comments and suggestions made at the OECD Forum in May 2018 and the SIG EGOV pre-ICIS Workshop in San Francisco in December 2018, where the concept of digital sclerosis was initially presented. In addition, we are grateful for academia and practitioners participating in talks and workshops held in Korea and Denmark discussing the challenges for government in the age of cognitive and digital automation technologies.

\section{REFERENCES}

[1] Scorpions. 1990. Composer, "Wind of Change. In Crazy World." [Sound Recording]. Mercury Records.

[2] K. Layne and J. Lee. 2001. Developing fully functional e-government: A four stage model. Government Information Quarterly 18, 2 (2001), 122-136.

[3] K. Andersen and H. Z. Henriksen. 2006. e-Government maturity models: Extension of the Layne and Lee model. Government Information Quarterly 23, 2 (2006), 236-248.

[4] T. H. Davenport. 2018. The AI advantage: How to Put the AI Revolution to Work. MIT Press, Cambridge, MA.

[5] M. Ford. 2015. Rise of the Robots: Technology and the Threat of a fobless Future. Basic Books, New York, NY.

[6] R. Susskind and D. Susskind. 2015. The Future of the Professions: How Technology Will Transform the Work of Human Experts. Oxford University Press.

[7] E. Brynjolfsson and A. McAfee. 2018. The Business of AI. MIT Press, Cambridge, MA.

[8] T. Tang and A. Ho. 2019. A path-dependence perspective on the adoption of Internet of Things: Evidence from early adopters of smart and connected sensors in the United States. Government Information Quarterly 36, 2 (April 2019), 321-332.

[9] NPR. 1997. Access America: Reengineering through information technology. National Partnership for Reinventing Government. Retrieved May 10, 2019 from https://govinfo.library.unt.edu/npr/library/announc/access/acessrpt.html.

[10] Cabinet Office. 2004. From E-Envoy to E-Government. Retrieved May 10, 2019 from https://web.archive.org/web/20061211122502/ http://www.cabinetoffice.gov.uk/newsroom/news_releases/2004/250504_egov.asp.

[11] E. Brynjolfsson and A. McAfee. 2014. The Second Machine Age: Work, Progress, and Prosperity in a Time of Brilliant Technologies. WW Norton \& Company.

[12] G. G. Parker, M. W. Van Alstyne, and S. P. Choudary. 2016. Platform Revolution: How Networked Markets Are Transforming the EconomyAnd How to Make Them Work for You. W. W. Norton \& Company, New York, NY.

[13] A. Sundararajan. 2016. The Sharing Economy: The End of Employment and the Rise of Crowd-Based Capitalism. MIT Press, Cambridge, MA.

[14] H. R. Ekiba and B. A. Nardi. 2017. Heteromation and Other Stories of Computing and Capitalism. MIT Press, Cambridge, MA.

[15] R. Blauner. 1964. Alienation and Freedom. University of Chicago Press.

[16] E. Chinoy. 1955. Automobile Workers and the American Dream. Doubleday \& Company.

[17] W. A. Faunce. 1965. Automation and the division of labor. Social Problems 13, 147-160.

[18] F. C. Mann and L. R. Hoffman. 1960. Automation and the Worker: A Study of Social Change in Power Plants. Henry Holt Publishers.

[19] C. R. Walker and R. H. Guest. 1952. The Man on the Assembly Line. Harvard University Press, Cambridge, MA.

[20] H. A. Simon. 1965. The Shape of Automation for Men and Management. Harper \& Row.

[21] J. N. Danziger. 1977. Computers and the frustrated chief executive. MIS Quarterly 1, 1 (1977), 44-53.

Digital Government: Research and Practice, Vol. 1, No. 1, Article 9. Publication date: January 2020. 
[22] D. H. Coursey and D. F. Norris. 2008. Models of e-government: Are they correct ? An empirical assessment. Public Administration Review 68, 3 (2008), 523-536.

[23] K. L. Kraemer and J. L. King. 2006. Information technology and administrative reform: Will e-government be different? International Journal of Electronic Government Research 2, 1 (2006), 1-20.

[24] R. Arendsen, O. Peters, M. Heede, and V. J. Dijk. 2014. Does e-government reduce the administrative burden of businesses? An assessment of business-to-government systems usage in the Netherlands. Government Information Quarterly 31, 1 (Jan. 2014 ), $160-169$.

[25] S. Kim. 2010. Public trust in government in Japan and South Korea: Does the rise of critical citizens matter? Public Administration Review 70, 5 (2010), 801-810.

[26] L. Lesrado, R. Vatrapu, and K. N. Andersen. 2016. A set theoretical approach to maturity models: Guidelines and demonstration. In Proceedings of the 37th International Conference on Information Systems.

[27] G. Lahrmann, F. Marx, R. Winter, and F. Wortmann. 2010. Business intelligence maturity models: An overview. In Proceedings of the 7th Conference of the Italian Chapter of AIS (itAIS'10).

[28] J. Becker, R. Knackstedt, and J. Poeppelbuss. 2009. Developing maturity models for IT management. Business \& Information Systems Engineering 1, 3 (2009), 213-222.

[29] J. Poeppelbuss and M. Roeglinger. 2011. What makes a useful maturity model? A framework of general design principles for maturity models and its demonstration in business process management. In Proceedings of the European Conference on Information Systems (ECIS'11).

[30] J. Lee. 2010. 10 year retrospect on stage models of e-government: A qualitative meta-synthesis. Government Information Quarterly 27, 3 (2010), 220-230.

[31] P. Dunleavy, H. Margetts, S. Bastow, and J. Tinkler. 2007. Digital Era Governance: IT Corporations, the State, and e-Government. Oxford University Press.

[32] United Nations. 2001. Benchmarking E-government: A Global Perspective. United Nations, Washington, DC.

[33] United Nations. 2003. UN Global e-Government Survey 2003. United Nations, Washington, DC.

[34] United Nations. 2008. UN Global e-Government Survey 2008: From e-Government to Connected Governance. United Nations, Washington, DC.

[35] NIA. 2018. 50-Year Footprints of Korean e-Government. National Information Society Agency. Retrieved May 4, 2019 from http://eng. nia.or.kr/site/nia_eng/ex/bbs/View.do?cbIdx=31975\&bcIdx=19674\&parentSeq=19674.

[36] T. B. Sørensen. 2019. Et halvt århundrede med dansk it. Ingeniøren. Retrieved May 3, 2019 from https://ing.dk/artikel/ et-halvt-arhundrede-med-dansk-it-78752.

[37] S. Zuboff. 1988. In the Age of the Smart Machine: The Future of Work and Power. Basic Books, New York, NY.

[38] United Nations. 2018. UN e-Government Survey 2018. Retrieved August 13, 2019 from https://publicadministration.un.org/egovkb/ en-us/Reports/UN-E-Government-Survey-2018.

[39] K. Goda and M. Kitsuregawa. 2012. The history of storage systems. Proceedings of the IEEE 100, 1433-1440.

[40] J. Lee. 2016. Evolution of digital government systems in the Republic of Korea. In Bringing Government into the 21st Century: The Korean Digital Governance Experience. World Bank, Washington, DC, 61-88.

[41] J. Lee and J. M. Moon. 2018. Coming age of digital automation: Backgrounds and prospects. In Transformation of Work in Asia-Pacific in the 21st Century. HKUST, Hong Kong, China, 11-56. Retrieved December 10, 2019 from https://apru.org/wp-content/uploads/2019/ 03/G18965 final.pdf.

[42] W. D. Eggers, D. Schatsky, and P. Viechnicki. 2017. How Artificial Intelligence Could Transform Government. Retrieved October 29, 2019 from https:/www2.deloitte.com/insights/us/en/focus/cognitive-technologies/artificial-intelligence-government-summary.html.

[43] H. Mehr. 2017. Artificial intelligence for citizen services and government. Harvard Kennedy School. Retrieved May 7 , 2019 from https://ash.harvard.edu/files/ash/files/artificial_intelligence_for_citizen_services.pdf.

[44] E. Wihlborg, H. Larsson, and K. Hedström. 2016. The computer says no! A case study on automated decision making in public authorities. In Proceedings of the 49th Hawaii International Conference on System Sciences. IEEE, Los Alamitos, CA.

[45] S. R. Barley, B. A. Bechky, and F. J. Milliken. 2017. The changing nature of work: Careers, identities, and work lives in the 21st century. Academy of Management Discoveries 3, 2 (2017), 111-115.

[46] L. P. Wilcocks and M. C. Lacity. 2016. Service Automation: Robots and the Future of Work. Steve Brookes Publishing.

[47] J. Manyika, M. Chui, M. Miremadi, J. Bughin, K. George, P. Willmott, and M. Dewhurst. 2017. A Future That Works: Automation, Employment, and Productivity. McKinsey Global Institute, New York, NY.

[48] A. Ross. 2016. The Industries of the Future. How the Next 10 Years of Innovation Will Transform Our Lives at Work and Home. Simon \& Schuster, London, UK.

[49] M. Beane and W. Orlikowski. 2015. What difference does a robot make? The material enactment of distributed coordination. Organization Science 26, 6 (2015), 1553-1573.

[50] D. H. Autor. 2015. Why are there still so many jobs? The history and future of workplace automation. fournal of Economic Perspectives 29, 3 (2015), 3-30,

[51] S. R. Barley and G. Kunda. 2001. Bringing work back. Organization Science 12, 1 (2001), 1-95.

Digital Government: Research and Practice, Vol. 1, No. 1, Article 9. Publication date: January 2020. 


\section{9:14 - K. N. Andersen et al.}

[52] I. Choi and M. C. Hoffman. 2017. Exporting South Korea's e-government experience. Public Administration Review 77, 5 (2017), $794-796$.

[53] T. Karippacheril, S. Kim, R. P. Beschel Jr., and C. Choi. 2016. Bringing Government into the 21st Century: The Korean Digital Governance Experience. World Bank Publications, Washington, DC.

[54] R. S. Wachal. 1971. Humanities and computers: A personal view. North American Review 256, 1, 30-33.

[55] G. Standing. 2011. The Precariat: The Dangerous New Class. Bloomsbury Academic.

[56] W. Dauth, S. Findeisen, J. Sudekum, and N. Wobner. 2019. German robots: The impacts of industrial robots on workers. Institute for Employment Research. Retrieved May 6, 2019 from http://doku.iab.de/discussionpapers/2017/dp3017.pdf.

[57] A. Ranerup and H. Z. Henriksen. 2019. Value positions viewed through the lens of automated decision-making: The case of social services. Government Information Quarterly. Forthcoming.

[58] M. Lipsky. 2010. Street-Level Bureaucracy. Russell Sage Foundation.

[59] A. Buffat. 2015. Street-level bureaucracy and e-government. Public Management Review 17, 1 (2015), 149-161.

[60] P. A. Busch and H. Z. Henriksen. 2018. Digital discretion: A systematic literature review of ICT and street-level discretion. Information Polity 23, 1 (2018), 3-28.

[61] T. L. Friedmann. 2005. The World Is Flat: A Brief History of the Twenty-First Century. Gardners Books.

[62] E. Raguseo, L. Gastaldi, and P. Neirotti. 2016. Smart work: Supporting employees' flexibility through ICT, HR practices and office layout. Evidence-Based HRM: A Global Forum for Empirical Scholarship 4, 3 (2016), 240-256.

[63] C. J. Bennett and C. D. Raab. 2018. Revisting the governance of privacy: Contemporary policy instruments in global perspective. Regulation and Governance (Sept. 2018), 1-18. Retrieved December 10, 2019 from https://doi.org/10.1111/rego.12222

[64] N. Fyle and J. Bannister. 1996. City watching: Closed circuit television surveillance in public spaces. Area 28, 1 (March 1996), 37-46.

[65] M. Foucault. 1975. Discipline and Punish: The Birth of the Prison. Random House, New York, NY.

[66] J. Bentham. 1798. Proposal for a New and Less Expensive Mode of Employing and Reforming Convicts. Retrieved May 6, 2019 from https://books.google.dk/books?id=9ZxEAAAAcAAJ\&pg=PA165\&lpg=PA165\&dq=Proposal+for+a+New+and+Less+Expensive+ mode+of+Employing + and + Reforming + Convicts\&source=bl\&ots=zrgjf15RqC\&sig=ACfU3U0zNE-dZqIPNU98pKevQTCPiirvuA\&hl=d $\mathrm{a} \& \mathrm{sa}=X \& v e d=2 \mathrm{ahUKEwjuzIjMgYziAhVFysQBHeRRCvcQ6AEwB3oECAcQAQ \# v=onepage \& q=Proposal \% 20for \% 20a \% 20New \% 20and \%}$ 20Less\%20Expensive $\% 20$ mode\%20 of\%20Employing\%20and\%20Reforming\%20Convicts\&f=false.

[67] A. C. Uzialko. 2019. The Best Employee Monitoring Software for 2019. Retrieved October 29, 2019 from https://www.business.com/ categories/employee-monitoring-software/.

[68] L. Rein. 2012. Stepped-Up Computer Monitoring of Federal Workers Worries Privacy Advocates. Retrieved May 7, 2018 from https://www.washingtonpost.com/politics/stepped-up-computer-monitoring-of-federal-workers-worries-privacy-advocates/2012/0 8/16/94392356-d816-11e1-91e1-eed6436f6d13_story.html?noredirect=on\&utm_term=.52150427a906.

[69] H. Z. Henriksen. 2018. One step forward and two steps back: e-Government policies in practice. In Policy Analytics, Modelling, and Informatics, J. R. Gil-Garcia, T. A. Pardo, and L. Luna-Reyes (Eds.). Springer, 79-97.

[70] J. Lee. 2017. The Impact of ICT on Work. Springer.

[71] G. Lee and Y. H. Kwak. 2012. An open government maturity model for social media-based public engagement. Government Information Quarterly 29, 4 (2012), 492-503.

[72] A. L. Kavanaugh, E. A. Fox, S. D. Sheetz, S. Yang, L. T. Li, D. J. Shoemaker, A. Natsev, and L. Xie. 2012. Social media use by government: From the routine to the critical. Government Information Quarterly 29, 4 (2012), 480-491.

Received May 2019; revised August 2019; accepted August 2019 